WellBeing International

WBI Studies Repository

$4-9-1990$

\title{
Long-Term Effects of Early Social Isolation in Macaca mulatta: Changes in Dopamine Receptor Function Following Apomorphine Challenge
}

\author{
Mark H. Lewis \\ University of North Carolina \\ John P. Gluck \\ University of New Mexico \\ Tom L. Beauchamp \\ University of New Mexico \\ Michael F. Keresztury \\ University of North Carolina \\ Richard B. Mailman \\ University of North Carolina
}

Follow this and additional works at: https://www.wellbeingintlstudiesrepository.org/acwp_arte

Part of the Animal Studies Commons, Other Animal Sciences Commons, and the Other Veterinary Medicine Commons

\section{Recommended Citation}

Lewis, M. H., Gluck, J. P., Beauchamp, A. J., Keresztury, M. F., \& Mailman, R. B. (1990). Long-term effects of early social isolation in Macaca mulatta: changes in dopamine receptor function following apomorphine challenge. Brain Research, 513(1), 67-73.

This material is brought to you for free and open access by WellBeing International. It has been accepted for inclusion by an authorized administrator of the WBI Studies Repository. For more information, please contact wbisr-info@wellbeingintl.org.

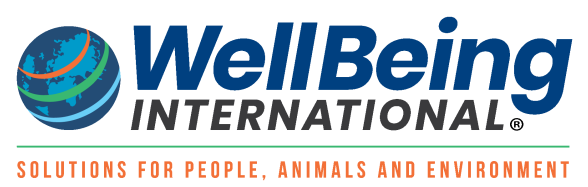




\title{
Long-Term Effects of Early Social Isolation in Macaca mulatta: Changes in Dopamine Receptor Function Following Apomorphine Challenge
}

\author{
Mark H. Lewis ${ }^{1}$, John P. Gluck ${ }^{2}$, Alan J. Beauchamp ${ }^{2}$, Michael F. Keresztury ${ }^{1}$, and Richard B. Mailman ${ }^{1}$ \\ ${ }^{1}$ University of North Carolina \\ ${ }^{2}$ University of New Mexico
}

\section{$\underline{\text { KEYWORDS }}$}

social isolation, apomorphine, non-human primate, dopamine receptor, cerebrospinal fluid, monoamine

\begin{abstract}
$\underline{\text { ABSTRACT }}$
The hypothesis that early social isolation results in long-term alterations in dopamine receptor sensitivity was tested using older adult rhesus monkeys. Isolated and control monkeys were challenged with apomorphine ( 0.1 and $0.3 \mathrm{mg} / \mathrm{kg}$ ), and the drug effects on spontaneous blink rate, stereotyped behavior, and self-injurious behavior were quantified using observational measures. Monoamine metabolites were quantified from cisternal CSF by HPLC-EC, prior to pharmacological challenge. Isolated and control monkeys did not differ in CSF concentrations of HVA, 5-HIAA, or MHPG. At the higher dose, apomorphine significantly increased the rate of blinking, the occurrence of whole-body stereotypies, and the intensity of stereotyped behavior (as measured by observer ratings) in isolated monkeys. The frequency of occurrence of self-injurious behavior was too low to allow for meaningful comparisons. These significant differences in response to apomorphine challenge support the hypothesis that long-term or permanent alterations in dopamine receptor sensitivity, as assessed by drug challenge, are a consequence of early social deprivation.
\end{abstract}

\section{INTRODUCTION}

Early prolonged isolation rearing of some species of non-human primates causes profound and permanent behavioral consequences. Rhesus monkeys reared in total or partial social isolation during the first year of life show deficits in affiliation, social responsiveness, communication, exploratory behavior, feeding and drinking, sexual and maternal behavior, and learning ability $2,4,19-21$. These animals also 
typically exhibit high rates of rocking, self-huddling, self-clasping, head rolling, self-biting and selfhitting $^{5,7,10,18}$, and the degree of impairment depends on both the duration of the social isolation and the age at which the animals are isolated ${ }^{25}$. Conversely, monkeys reared with access to adults and peers are behaviorally similar to fetal animals ${ }^{1,12}$. The deficits caused by social isolation persist into adulthood, and are not reversed unless atypical social experiences such as exposure to younger, socially immature animals are provided ${ }^{20,26,27}$. Sackett et al. ${ }^{22}$ have noted that such differential early social experience has profound effects on rhesus monkeys and chimpanzees, whereas other non-human primate species (e.g., pig-tailed macaques) are less impaired.

The isolated rhesus monkey thus provides a very useful model system by which to study long-term, functional changes associated with differential early social experience. Despite the large literature describing the behavioral sequelae of early social isolation, relatively little information is available concerning neurobiological mechanisms mediating the effects of such early deprivation. The spontaneous stereotyped behavior so characteristic of the 'isolation syndrome' led us to hypothesize that early social deprivation resulted in long-term changes in dopamine receptor sensitivity. Although direct evidence for this hypothesis has been lacking, potentiated responses to dopamine agonists and increases in dopamine receptor density have been reported in rodents socially isolated at the time of weaning ${ }^{11,23,29}$. In the present study, the hypothesis of long-term alterations in dopamine receptor function was tested by challenging older adult, isolated and socially reared monkeys, with the direct acting dopamine agonist, apomorphine. In addition, in order to evaluate whether isolation-induced receptor changes might be associated with alterations in dopamine transmission, concentrations of monoamine metabolites from cisternal cerebrospinal fluid (CSF) were determined by high performance liquid chromatography (HPLC) with electrochemical detection. These determinations were made prior to drug challenge.

\section{MATERIALS AND METHODS}

\section{Experimental subjects}

Sixteen rhesus monkeys (Macaca mulatta) were used as subjects. All monkeys (isolates and social controls) had previously participated in tests of learning (discrimination training in the Wisconsin General Test Apparatus) and social behavior (naturalistic observation of brief multianimal encounters). Animals were housed in individual cages $(76 \times 105 \times 76 \mathrm{~cm})$ in colony rooms, thereby allowing for visual, olfactory, and auditory exposure to conspecifics. Colony rooms were maintained at ca. $21{ }^{\circ} \mathrm{C}$ and $60 \%$ humidity with a $12 \mathrm{~h}$ light-dark cycle. Subjects were fed twice daily (08.00 and $15.30 \mathrm{~h}$ ) and water was available ad libitum.

Isolated monkeys $(n=8)$ were randomly selected from a population of 13 monkeys reared for the first 9 months of life in total social isolation. The specific details regarding the rearing of these animals has been presented elsewhere ${ }^{21}$ and will be reviewed only briefly here. Infants were removed from their mothers and placed in individual isolation cages (60 $\times 60 \times 60 \mathrm{~cm}$ stainless steel chambers) that constituted the housing for these monkeys for the next 9 months of life. Initially, infants experienced limited handling to facilitate feeding (i.e., the first 20 days in isolation), after which no handling occurred. Therefore, the sole sources of varied stimulation were provided by food, periodic cage maintenance, and by the animal's selfproduced stimulation, such as moving, climbing about the cage, and visually exploring the cage interior. Light was provided on a typical $12 \mathrm{~h}$ cycle. The age of the isolated animals ranged between 18 and 21 years (mean $=19.5$ ) at the beginning of the study. The isolated group was made up of 3 females and 5 males.

Socially reared animals $(n=8)$ were randomly selected from a population of 20 monkeys reared with peer and maternal contact. At the start of the experiment, the age of the socially reared controls was between 
14 and 19 years (mean $=16.5$ ); 2 females and 6 males made up the socially reared group. Housing conditions for both isolates and social controls were identical after the first 9 months of life.

\section{Determination of monoamine metabolites in CSF}

CSF samples, obtained prior to the initiation of the pharmacological challenge studies, were assayed to determine whether monoamine metabolite concentrations differed between isolates and socially reared controls. On the day CSF was obtained, the $08.00 \mathrm{~h}$ feeding was withheld. Between 09.30 and $10.30 \mathrm{~h}$ the subjects were anesthetized with ketamine $\mathrm{HCl}(10.0 \mathrm{mg} / \mathrm{kg}$ i.m.), held in the lateral decubitus position, and a $2 \mathrm{ml} \mathrm{CSF} \mathrm{sample} \mathrm{was} \mathrm{obtained} \mathrm{by} \mathrm{percutaneous} \mathrm{puncture} \mathrm{to} \mathrm{the} \mathrm{cisterna} \mathrm{magna} \mathrm{(see} \mathrm{Shelton} \mathrm{et}$

al. $^{24}$ ). Bacopoulos et $\mathrm{al}^{3}$ have demonstrated that 15 rain after administration this dose of ketamine did not significantly alter the concentration of the acid metabolites in monkey CSF, but it did increase the concentrations after $4 \mathrm{~h}$. CSF samples used in this study were taken 5-28 min after ketamine administration. Samples were centrifuged, placed on dry ice and then stored at $-70^{\circ} \mathrm{C}$ until assayed.

\section{CSF monoamine metabolite determinations}

Concentrations of homovanillic acid (HVA), 5-hydroxyindoleacetic acid (5-HIAA), and 3-methoxy-4hydroxyphenylglycol (MHPG) were determined in each sample by a modification of the method of Van Bockstaele et al. $^{28}$, using high-performance liquid chromatography with electrochemical detection. The eluent was modified by addition of $0.05 \mathrm{M} \mathrm{NaH}_{2} \mathrm{PO}_{4}, 0.1 \mathrm{mM}$ EDTA, and $7.0 \%$ methanol, with $\mathrm{pH}$ adjusted to 4.2 with glacial acetic acid. Samples were deproteinized by adding $100 \mu \mathrm{l}$ of $2.4 \mathrm{M} \mathrm{HClO}_{4}$ to $250 \mu \mathrm{l}$ of CSF. CSF samples were cooled for $30 \mathrm{~min}$ and centrifuged for $10 \mathrm{~min}$ at 10,000 $\mathrm{g}$, a $250 \mu \mathrm{l}$ aliquot was mixed with $50 \mu \mathrm{l}$ of $5.0 \mathrm{M}$ sodium acetate, and $250 \mu \mathrm{l}$ of this was injected into the liquid chromatograph.

Blank-corrected standard curves for the quantification of all compounds were prepared by analyzing a series of standard solutions containing a fixed amount of the internal standard (5-hydroxyindolecarboxylic acid) and varying amounts of each analyte. The standard solutions, in appropriate volumes of mobile phase, were subjected to the identical preparative steps used to assay unknown CSF samples. Sample concentrations were determined mathematically from the area-under-the-curve relative to the appropriate internal standards, using the slope and intercept of the standard curve obtained by regression analyses (routinely, $r \geq 0.99$ ).

\section{Behavioral observations}

Prior to initiation of baseline data collection, subjects were habituated to observer presence for 10 daily 5 min sessions. During this time the observer fed the animals small amounts of highly preferred treats. To establish a baseline, the frequency of spontaneous eye blinks (EB), stereotyped behaviors (SB), and selfinjurious behavior (SIB) were observed and recorded while monkeys were in their home cages.

Measurement of spontaneous eye blinking. Recently, a number of studies have examined the hypothesis that spontaneous EB is, at least in part, under the control of dopamine neurons in the basal ganglia (see Karson $^{13}$ and Karson et al. ${ }^{14}$ for reviews of the evidence supporting such a conclusion). Thus, spontaneous blink rates provide a method for assessing central dopamine function that is both noninvasive and easily quantifiable.

Two independent observers, seated $1.20 \mathrm{~m}$ from the subjects' home cage encoded on a checksheet the frequency of spontaneous EBs for each animal for a 2 min observation period. Each animal was observed at 09.30 and $14.30 \mathrm{~h}$ on 10 separate occasions. An EB was defined as the complete and simultaneous closure of both eyes followed by the opening of both eyes. A two minute sample was used in the analysis 
only if the monkey's face was in full view for the entire period. The frequency of EB during two rain observational periods was recorded with continuous real time measurement.

Measurement of stereotyped and self-injurious behavior. SB was scored whenever monkeys engaged in the same behavioral sequence three or more times consecutively (e.g., rocking, swaying, pacing, etc.), whereas SIB was scored when animals were observed to bite themselves, bang their head, or scrape themselves against the sides or floor of the home cage. No injuries were observed to occur as the result of these behaviors.

A modified frequency time sampling method was used to measure SB and SIB. This latter technique involved dividing two min observational periods into eight $15 \mathrm{~s}$ scoring intervals. At the end of each scoring interval, a tone was emitted from an interval timer signalling the observer to score any SB or SIB observed during the preceding $15 \mathrm{~s}$. Therefore, the maximum frequency possible for SB or SIB during a two min observational period was 8. Observational data for this and all other phases of the study were collected by a single observer positioned directly in front of the subject's home cage. At the conclusion of the observational period, data were transmitted from the digital data collector memory to a permanent file using a laboratory microcomputer.

\section{Interobserver reliability}

To facilitate the establishment of inter-rater reliability, all subjects were videotaped throughout the procedure. With the exception of EB data, randomly selected tapes (one from each group at all testing conditions) were scored for target behaviors by two independent observers uninformed as to rearing history and testing condition. Interobserver agreement for SB and SIB was analyzed using both percent agreement measures as well as Cohen's $\kappa$, which corrects for agreement by chance. For EB data, two observers were assigned to score, at random intervals, the same animal simultaneously. As these data were not amenable to $\kappa$ analysis, only a measure of percent agreement was calculated.

\section{Drug administration}

Animals were transported from their home cage in a carrying cage, and then weighed. Following weighing, the individuals were carefully placed in a restraint device and administered the vehicle $(0.1 \%$ ascorbate) or active drug ( 0.1 or $0.3 \mathrm{mg} / \mathrm{kg}$ apomorphine, free base) by intramuscular injection. To decrease the probability that target behaviors would be altered as a function of transporting and restraining monkeys, all animals were habituated to this procedure once a day for the 5 days immediately prior to vehicle and drug administration. When compared to baseline, statistical analysis showed this experience did not change the frequency of emitted target behaviors (all $F$-values $<1.00$ ). On the next two days following completion of the habituation procedure, monkeys were injected with drug or vehicle, and again observed in their home cages. The doses selected were based on previous experience using apomorphine in the study of dopamine receptor supersensitivity in rodents. Following weighing, restraint, and injection, the animals were returned to the home cage. Observational testing was initiated after a 20 min waiting period. Each animal received both doses $(0.1$ and $0.3 \mathrm{mg} / \mathrm{kg}$ ) with the dose order being counterbalanced. A minimum of 30 days separated each experimental condition.

\section{Statistical analysis}

The effect of rearing condition on CSF monoamine metabolites was determined by Student's $t$-test. For behavioral data, the effects of rearing history, test condition, and their interaction were tested using a $2 \times$ 4 analysis of variance (ANOVA) with repeated measures on one factor (test condition). Post-hoc analyses of significant interactions were conducted using a simple main effects test. 


\section{RESULTS}

Effects of isolation on monoamine metabolites in CSF

CSF concentrations of HVA, an acidic metabolite of dopamine, as well as 5-HIAA and MHPG, the major metabolites of serotonin and norepinephrine, respectively, were determined by HPLC with electrochemical detection (see Fig. 1). These determinations were made using samples collected prior to apomorphine challenge. No significant differences in the concentrations of these monoamine metabolites were found as a function of rearing condition.

\section{Interobserver reliability}

The results of both percent agreement (94\%) and Cohen's $k(k=0.87, z=13.8, P<0.001)$ indicated that interrater agreement for the scoring of SB and SIB was quite high. The degree of interrater agreement for the scoring of spontaneous blink rate was also quite high (96\%).

Fig. 1. Concentrations $(\mathrm{ng} / \mathrm{ml})$ of monoamine metabolites (mean \pm S.E.M.) in cisternal CSF sampled from isolated and socially reared monkeys. No statistically reliable differences were found for HVA $\left(t_{19}=1.54\right), 5$ HIAA $\left(t_{19}=0.14\right)$, or MHPG $\left(t_{19}=0.8\right)$.

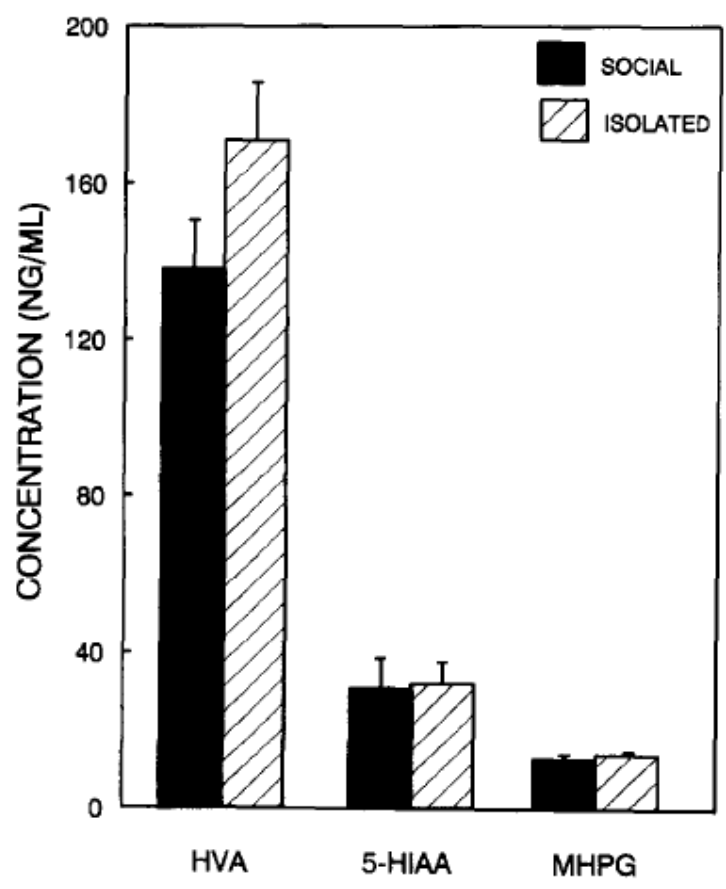

\section{Effects of isolation on apomorphine-induced eye blinking}

Fig. 2 displays the mean number of spontaneous eye-blinks observed in a 2 min period for isolated and control monkeys under all experimental conditions. As can be seen from the figure, no difference between groups was apparent during the baseline or vehicle conditions. As anticipated, apomorphine administration substantially increased blink rate $\left(F_{3,42}=26.66, P<0.001\right)$. Although no main effect for rearing history was found, a statistically reliable rearing history by test condition interaction $\left(F_{3,42}=5.72, P\right.$ $<0.01$ ) was found. This result was due to the significantly higher frequency of spontaneous blinking demonstrated by isolated monkeys relative to their socially reared counterparts following the higher drug dose $\left(F_{1,14}=5.88, P<0.05\right)$. 
Further analyses of these data yielded a significant dose order by rearing history interaction for the higher dose of apomorphine $\left(F_{1,6}=12.01, P<0.05\right)$. Thus, comparisons were made between drug-naive isolated and social animals at each dose. This result confirmed that no significant difference in EB was found at the lower dose of apomorphine, whereas a statistically significant difference was found between isolates and social animals at the higher dose $\left(F_{1,6}=10.1, P<0.05\right)$.

Fig. 2. Mean frequency ( \pm S.E.M.) of spontaneous EB per 2 min period in isolated and control monkeys. Asterisk indicates significantly increased blink rate relative to social controls.

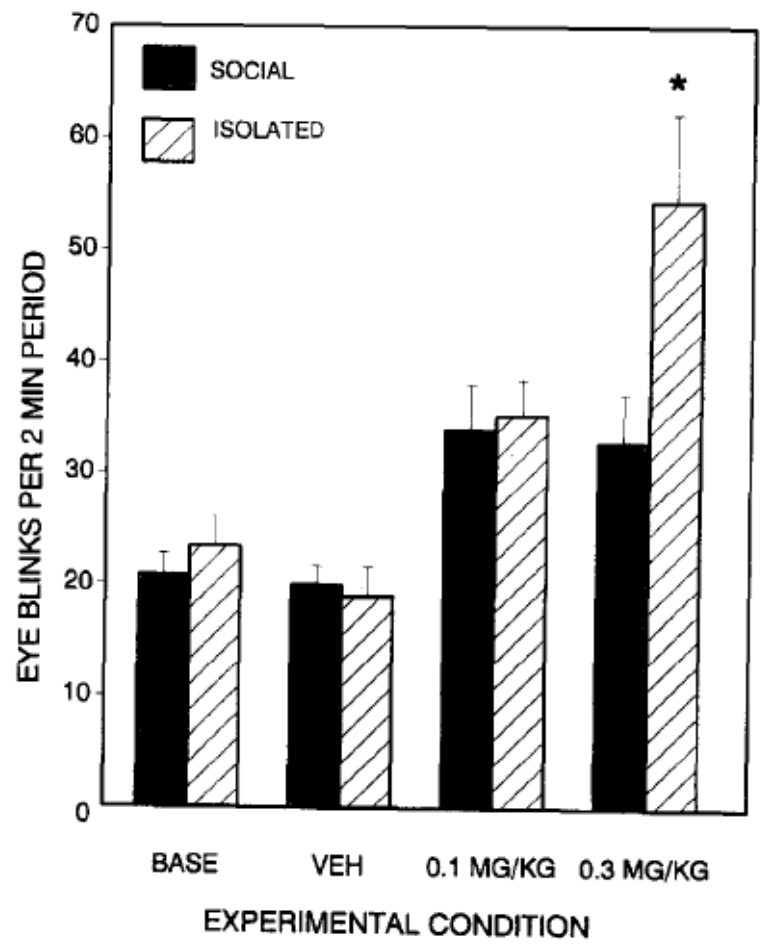

Effects of isolation on apomorphine-induced stereotyped behavior

As depicted in Fig. 3, SB was expressed as the mean modified-frequency score obtained for each condition. The repeated measures ANOVA revealed a main effect for testing condition $\left(F_{3,42}=13.8, P<\right.$ 0.001 ), reflecting a significant drug-induced increase in SB for both groups. While there was a tendency for isolated monkeys to display increased rates of SB across all experimental conditions when compared to controls, statistical analysis failed to yield a significant main effect for rearing history. Moreover, there was no evidence for a rearing history by testing condition interaction, suggesting that the drug treatment had no differential effect on isolate monkeys.

Subsequent analyses of these data yielded a significant dose order effect for the lower dose of apomorphine $\left(F_{1,6}=23.7, P<0.01\right)$. Thus, comparisons were made between drug-naive isolated and social animals at each dose $(n=4)$. This analysis confirmed that no significant difference in SB was found at either dose of apomorphine.

However, a more detailed look at the data suggests that apomorphine did indeed have differential effects on SB as a function of rearing condition. Apomorphine administration induced both whole body stereotypies as well as oral stereotypies. The latter, which included tongue thrusting, lip smacking, and 
chewing, was infrequently observed during baseline or vehicle conditions but occurred significantly more frequently $\left(F_{1,56}=31.4, P<0.001\right)$ than whole body stereotypies following apomorphine (see Fig. 4 ).

Fig. 3. Mean modified frequency ( \pm S.E.M.) of stereotyped behavior in isolated and control monkeys.

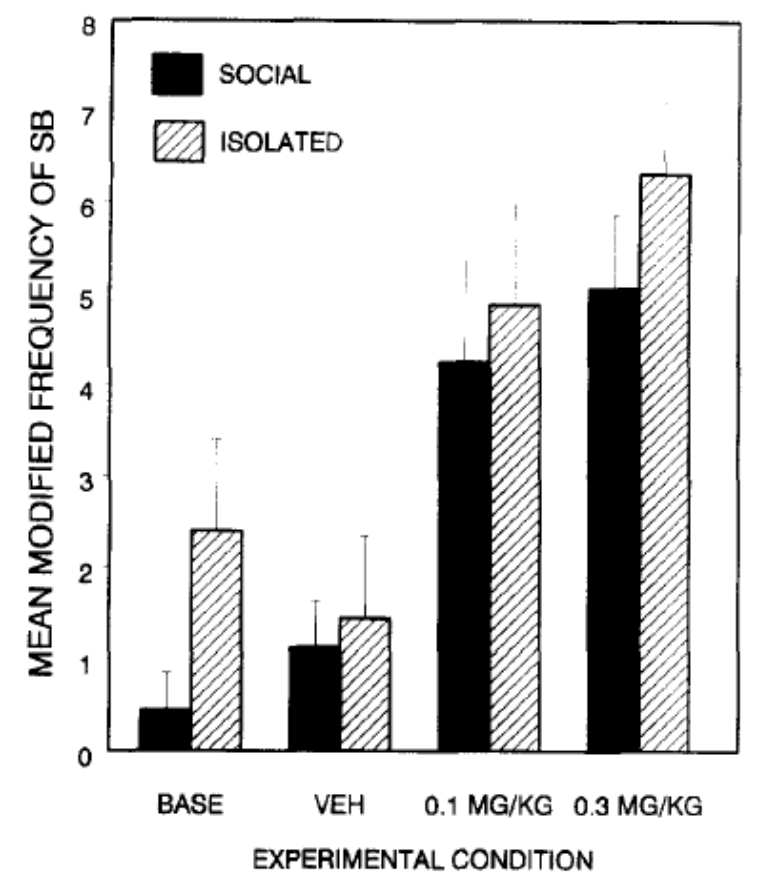

Fig. 4. Mean modified frequency ( \pm S.E.M.) of whole body and oral stereotyped behavior in isolated and control monkeys. Asterisk indicates significantly increased frequency of whole body stereotypies in isolated animals relative to social controls.

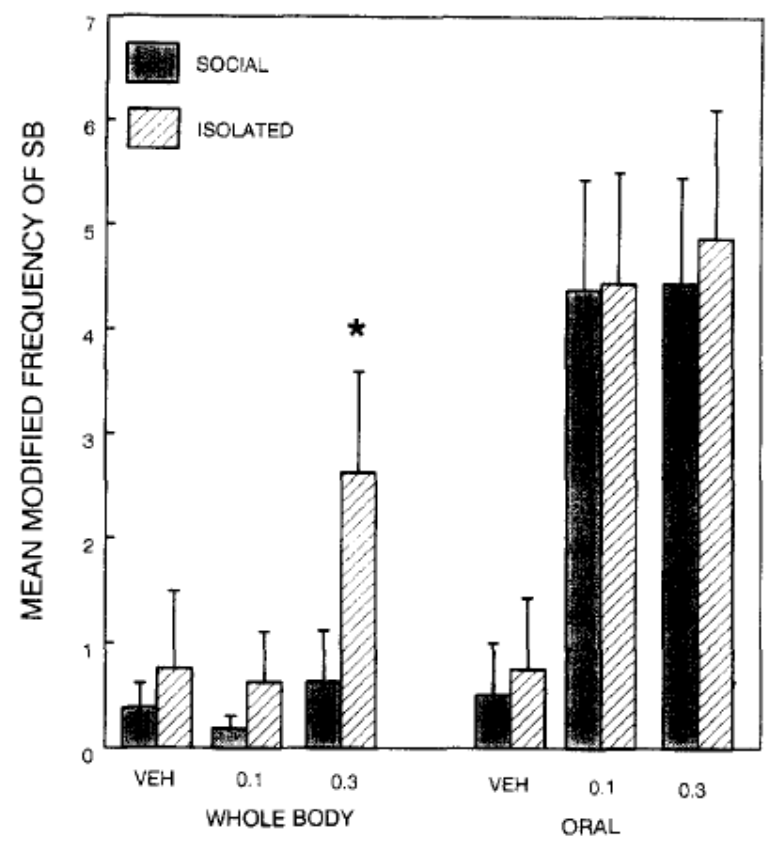

EXPERIMENTAL CONDITION 
Fig, 5. Mean intensity ratings (+ S.E.M.) of stereotyped behavior in isolated and control monkeys. Asterisk indicates significantly increased intensity ratings relative to social controls.

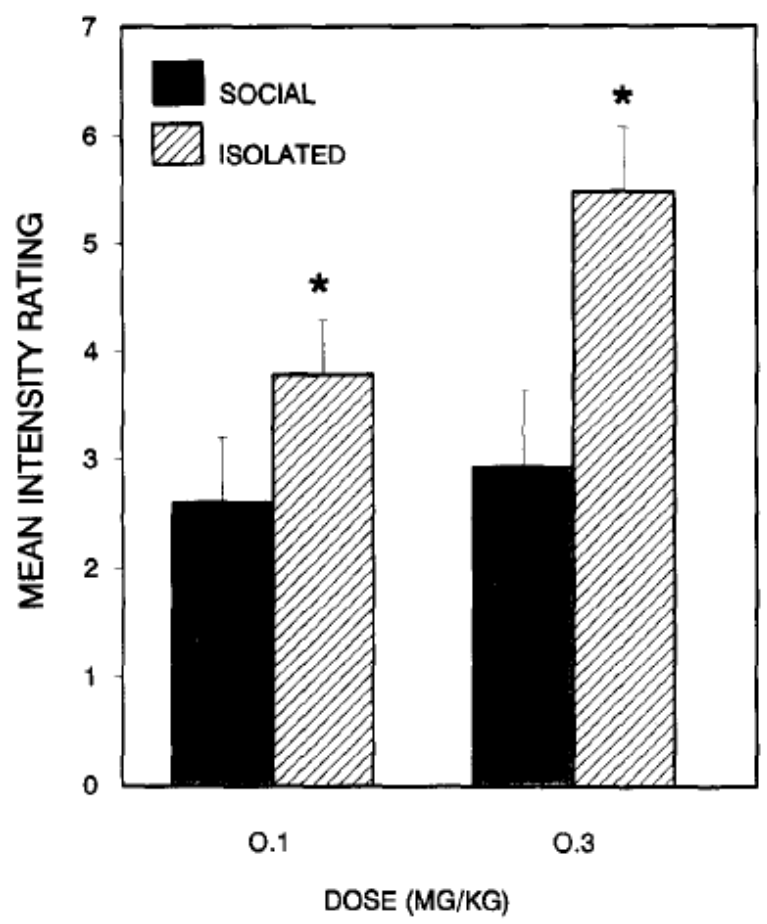

Fig. 6. Mean modified frequency ( \pm S.E.M.) of self-injurious behavior in drug-naive isolated and control monkeys.

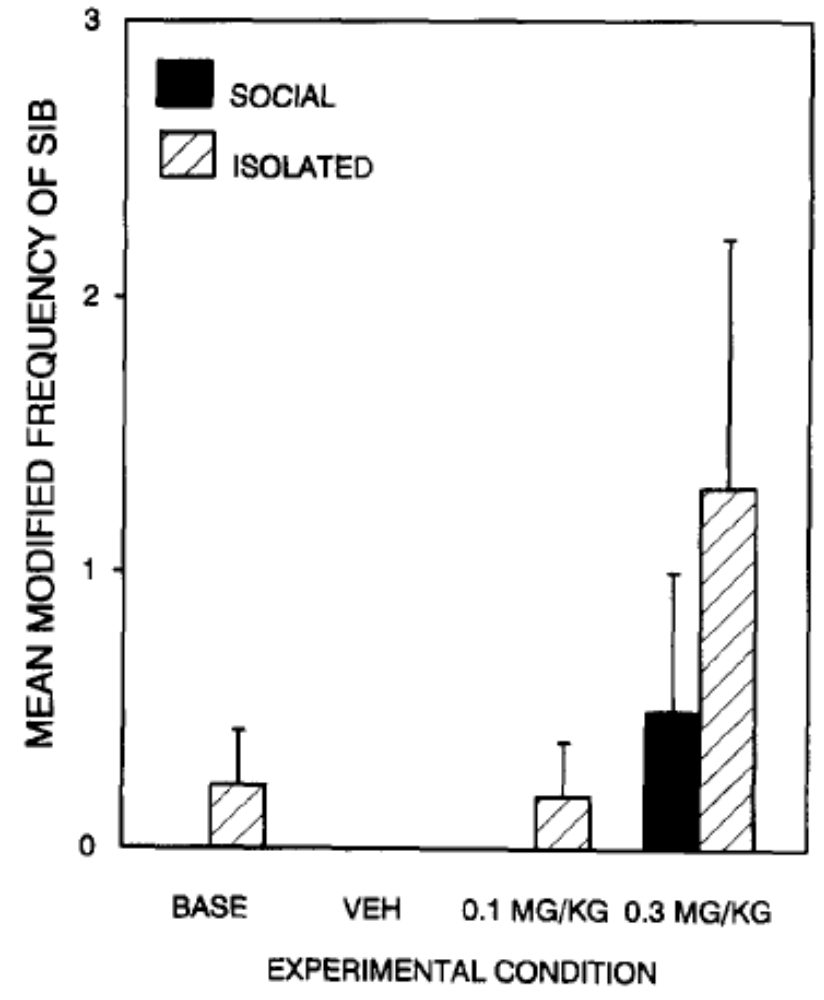


Thus, analyses were conducted to determine whether the proportion of type of stereotypy was altered by either dose or rearing history. As can be seen from Fig. 4, while oral stereotypies did not appear to differ due to either dose or rearing history, whole body stereotypies were much more prevalent in isolated monkeys at the $0.3 \mathrm{mg} / \mathrm{kg}$ dose. A Fischer's exact probability test $(P=0.02)$ confirmed that a significantly greater number of isolated monkeys exhibited whole body stereotypies at this dose.

Apomorphine also appeared to have a differential effect on the intensity of SB exhibited by isolated vs control animals. To quantify this behavioral dimension, intensity was scored by trained observers using a 7-point Lickert-type rating scale. These data (see Fig. 5) were then entered into a two factor repeated measures ANOVA (rearing history by dose). This analysis yielded a significant main effect for dose $\left(F_{1,14}\right.$ $=4.3, P=0.05$ ), indicating higher intensity SB at the $0.3 \mathrm{mg} / \mathrm{kg}$ dose. A significant main effect for rearing history was also found $\left(F_{1,14}=6.4, P<0.05\right)$ demonstrating that, across both dose levels, isolated monkeys exhibited significantly more intense SB than was observed for socially reared control animals. Agreement between raters was measured for this intensity variable and was found to be quite high $(r=$ 0.94).

\section{DISCUSSION}

The present results provide support for the hypothesis of long-term changes in the sensitivity of central dopamine receptors, as estimated by apomorphine challenge, induced by early social deprivation of rhesus monkeys. Cisternal CSF monoamine metabolite concentrations, examined prior to any drug challenge, were not different in isolated animals relative to control monkeys. This discrepancy was not unexpected, as it must be remembered that such measurements, especially if probenicid pretreatment is not used, would likely only show differences if there were large changes in dopamine metabolism. Moreover, a recent study by Elsworth et al. ${ }^{6}$ supports the conclusion that cisternal CSF concentrations may not reflect changes in major dopamine terminal fields such as the caudate-putamen. These investigators reported that, in vervet monkeys, CSF HVA concentrations were found to correlate only with HVA concentrations in the dorsal frontal cortex.

Appropriate pharmacological or environmental challenge studies that resulted in substantial changes in dopamine metabolism would be needed to affect differentially this in vivo estimate of monoamine activity. Kraemer et al. ${ }^{15}$ used such a strategy and reported significantly increased CSF norepinephrine concentrations in socially isolated rhesus monkeys following amphetamine administration.

The apomorphine challenge data are consistent with the hypothesis that early prolonged social isolation results in long-term alterations in a functional dopamine receptor supersensitivity. The spontaneous EB data provided the clearest evidence of such supersensitivity. At the higher dose of apomorphine, isolated animals were observed to blink, on the average, 2-3 times their baseline rate in a 2 min period, whereas control monkeys showed no further increase over their rate measured for the lower dose. It is interesting to note that no reliable differences in blink rate were observed between isolated and social animals during the baseline and vehicle conditions. This result is in contrast to data collected on schizophrenics ${ }^{13}$ and mentally retarded persons who exhibited high rates of stereotyped behavior ${ }^{17}$. These clinical disorders are both thought to involve alterations in dopamine receptor function. It is not at all unusual, however, that an environmental or pharmacological challenge is required in order to see the functional consequences of alterations in receptor function.

The effects of apomorphine on SB also support the hypothesis of long-term dopamine receptor changes in isolated monkeys. Although the overall frequency of SB was not markedly different for isolate monkeys, the intensity of SB observed in total isolates was rated as far greater than that observed in control monkeys. Additionally, apomorphine administration induced both whole body stereotypies (rocking, 
pacing, etc.) as well as oral stereotypies (lip smacking, tongue thrusting, etc.). Oral stereotypies, though significantly more frequently observed than whole body stereotypies, did not discriminate dose or rearing history, while whole body stereotypies did increase markedly at the higher drug dose and only in isolates. Thus, isolate monkeys showed a potentiated response to apomorphine challenge both in the intensity of SB and in the frequency of whole body stereotypies.

SIB did not prove to be a particularly useful endpoint in testing our hypothesis. While more self-injury was observed in isolated animals $(n=3)$ than was observed in controls $(n=1)$, no overall statistically reliable differences in SIB were noted. The doses of apomorphine were presumably too small to induce this behavior reliably.

In addition to providing support for the hypothesis of long-term alterations in dopamine receptor sensitivity, the present results also support the mediation by dopamine of spontaneous EB, SB, and, to a lesser extent, SIB. Isolation-induced SB and SIB provide, we believe, a useful model of the pathological stereotypies and self-injury frequently seen in mentally retarded and autistic persons ${ }^{16}$. The present data provide the first clear demonstration of long-term functional alterations in dopamine receptor sensitivity in non-human primates following social isolation. The neurobiological mechanisms mediating such changes (e.g., increased density or sensitivity of post-synaptic dopamine receptors) remain to be elucidated. In vitro experiments currently in progress will test these and other potential mechanisms.

\section{Acknowledgements}

This research was supported, in part, by PHS Grant MH42938 and by Center Grants HD03110 and $\mathrm{MH} 33127$.

\section{REFERENCES}

Anderson, C.O. and Mason, W.A., Early experience and complexity of social organization in groups of young rhesus monkeys (Macaca mulatta), J. Comp. Physiol. Psychol., 87 (1974) 681-690.

Arling, G.L. and Harlow, H.E, Effects of social deprivation on maternal behavior of rhesus monkeys, $J$. Comp. Physiol. Psychol., 64 (1967) 371-377.

Bacopoulos, N.G., Redmond, D.E. and Roth, R.H., Serotonin and dopamine metabolites in brain regions and cerebrospinal fluid of a primate species: effects of ketamine and fluphenazine, J. Neurochem., 32 (1979) 1215-1218.

Beauchamp, A.J. and Gluck, J.P., Associative processes in differentially reared monkeys (Macaca mulatta): sensory preconditioning, Dev. Psychobiol., 21 (1988) 355-364.

Berkson, G. and Mason, W.A., Stereotyped behaviors of chimpanzees: relation to general arousal and alternate activities, Percept. Motor Skills, 18 (1964) 635-652.

Elsworth, J.D., Leahy, D.J., Roth, R.H. and Redmond, D.E., Homovanillic acid concentrations in brain, CSF and plasma as indicators of central dopamine function in primates, J. Neural Trans., 68 (1987) 5162.

Fitz-Gerald, E, Effects of D-amphetamine upon behavior in young chimpanzees reared under different conditions. In H. Brill and J. Cole (Eds.), Neuropsychopharmacology, Vol. 5, Elsevier, Amsterdam, 1967.

Gluck, J.P. and Pearce, H.E., Acquisition and extinction of an operant response in differentially reared rats, Dev. Psychobiol., 10 (1977) 143-149. 
Gluck, J.P., Harlow, H.E and Schiltz, K.A., Differential effect of early enrichment and deprivation on learning in the rhesus monkey (Macaca mulatta), J. Comp. Physiol. Psychol., 75 (1973) 403-407.

Gluck, J.P., Otto, M.N. and Beachamp, A.J., Respondent conditioning of self-injurious behavior in early socially deprived rhesus monkeys ( Macaca mulatta), J. Abhor. Psychol., 94 (1985) 222-226.

Guisado, E., Fernandez-Tome, P., Garzon, J. van DelRio, J., Increased dopamine receptor binding in the striatum of rats after long-term isolation., Eur. J. Pharmacol., 65 (1980) 463-464.

Harlow, H.E and Harlow, M.K., The affectional systems. In A.M. Scrier, H.E Harlow and E Stollnitz (Eds.), Behavior of Non-Human Primates, Academic, New York, 1965, pp. 287-334.

Karson, C.N., Spontaneous eye-blink rates and dopaminergic systems, Brain, 106 (1983) 643-653.

Karson, C.N., Staub, R.A., Kleinman, J.E. and Wyatt, R.J., Drug effect on blink rates in rhesus monkeys: preliminary studies, Biol. Psychiat., 16 (1981) 249-254.

Kraemer, G.W., Ebert, M.H., Lake, C.R. and McKinney, W.T., Hypersensitivity to d-amphetamine several years after early social deprivation in rhesus monkeys, Psychopharmacology, 82 (1984) 266-271.

Lewis, M.H. and Baumeister, A.A., Stereotyped mannerisms in mentally retarded persons: animal models and theoretical analyses. In N.R. Ellis (Ed.), International Reviews on Research of Mental Retardation, Vol. 11, Academic Press, New York, 1982, pp. 123-161.

MacLean, W.E., Jr., Lewis, M.H., Bryson-Brockmann, W.A., Ellis, D.N., Arendt, R.E. and Baumeister, A.A., Blink rate and stereotyped behavior: evidence for dopamine involvement?, Biol. Psychiat., 20 (1985) 1321-1325.

McKinney, W.L., Young, L.D., Soumi, S.J. and Davis, J.M., Chlorpromazine treatment of disturbed monkeys, Arch. Gen. Psychiat., 29 (1973) 490-494.

Miller, R.E., Caul, W.F. and Mirsky, I.A., Patterns of eating and drinking in socially isolated rhesus monkeys, Physiol. Behav., 7 (1971) 127-134.

Novak, M.A. and Harlow, H.F., Social recovery of monkeys isolated for the first year of life: 1. Rehabilitation and therapy, Dev. Psychol., 11 (1975) 453-465.

Sackett, G.P., The persistence of abnormal behaviors in monkeys following isolation rearing. In R. Porter (Ed.), CIBA Foundation Symposium on the Role of Learning in Psychotherapy, Churchill, London, 1968.

Sackett, G.P., Holm, R.A. and Ruppenthal, G.C., Social isolation rearing: species differences in behavior of macaque monkeys, Dev. Psychol., 12 (1976) 283-288.

Sahakian, B.J., Robbins, T.W., Morgan, M.J. and Iversen, S.D., The effects of psychomotor stimulants on stereotypy and locomotor activity in socially-deprived and control rats, Brain Research, 84 (1975) 195205.

Shelton, S.E., Kalin, N.H., Gluck, J.P., Keresztutry, M.E, Schneider, V.A. and Lewis, M.H., Effect of age on cisternal cerebrospinal fluid concentrations of monoamine metabolites in nonhuman primates, Neurochem. Int., 13 (1988) 353-357.

Soumi, S.J. and Harlow, H.F., Abnormal social behavior in young monkeys. In J. Hellmuth (Ed.), The Exceptional Infant, Vol. 2, Bruner-Mazel, New York, 1971. 
Soumi, S.J. and Harlow, H.F., Social rehabilitation of isolate-reared monkeys, Dev. Psychol., 6 (1972) 487-496.

Soumi, S.J., Harlow, H.F. and Novack, M.A., Reversal of social deficits produced by isolation rearing in monkeys, J. Human Evol., 3 (1974) 527-534.

Van Bockstaele, M., Dillen, L., Claeys, M. and De Potter, W.P., Simultaneous determination of the three major monoamine metabolites in cerebrospinal fluid by high performance liquid chromatography with electrochemical detection, J Chromatogr. Biomed. Appl., 275 (1983) 11-20.

Weinstock, M., Speiser, Z. and Ashkenazi, R., Changes in brain catecholamine turnover and receptor sensitivity induced by social deprivation in rats, Psychopharmacology, 56 (1978) 205-209. 